\title{
MEASUREMENT OF WOOD MOISTURE CONTENT USING THE COLMAN ELECTRODE ${ }^{1}$
}

\author{
BY W. J. BLOOMBERG ${ }^{2}$ and D. FARRELL ${ }^{3}$
}

\section{ABSTRACT}

Colman electrodes were inserted into stem sections of Douglas-fir, western hemlock, western red cedar and black cottonwood and resistance readings were taken at wood moisture contents of $10 \%$ to $100 \%$ of maximum moisture content. In almost all the conifer sections tested, $85 \%$ or more of the readings lay within limits of $\pm 10 \%$ moisture content about the mean curve, and over $50 \%$ were within $\pm 5 \%$. The variation was greater for black cottonwood. Variation was also greater in the larger than in the smaller sections. The curves for individual sections within each species had certain characteristics in common, but no two curves were identical.

Resistance readings given by Colman electrodes inserted into living black cottonwood trees showed a fairly good correlation with soil moisture content when the trees were subjected to cycles of drought and watering.

\section{INTRODUCTION}

In contrast to gravimetric methods of wood moisture determination, electrical methods are rapid and non-destructive. However, existing electrical techniques, based on measuring the conductivity of wood, are useless for moisture contents above approximately $30 \%$ because the relationship between wood moisture and resistance becomes erratic (Keylwerth and Noack 1950; James 1958; Johnston and Wynands 1958; Moses and Scheffer 1959). The Colman electrode, developed to measure soil moisture (Colman 1947), appeared to offer a means of measuring wood moisture over a wider range than was previously possible. It is not dependent on the conductivity of the external medium for moisture measurement but instead measures the current passing through a standardized square of fibreglas which absorbs moisture. The electrode is small, compact, and of a suitable shape for inserting into wood.

The objective of this investigation was to ascertain whether readings with the Colman electrode would indicate accurately the moisture content of wood sections or of living trees from near-dryness to saturation.

\footnotetext{
${ }^{1}$ Contribution No. 1134, Forest Entomology and Pathology Branch, Department of Forestry, Ottawa, Canada.

${ }^{2}$ Forest Research Laboratory, 506 W. Burnside Road, Victoria, B.C.

${ }^{\mathrm{s}}$ Present address: Faculty of Agriculture, University of British Columbia, Vancouver, B.C.
} 


\section{Wood sections}

\section{Methods and MAterials}

The meter used to measure the electrical current passing through the electrodes was the soil moisture ohm meter Model 300, an alternating current type giving readings in micro-amps. The electrodes were Model 351, consisting of a sandwich of Monel screens interleaved with fiberglas and incorporating a thermistor for temperature measurement. Prior to use, the electrodes were washed in a detergent solution, rinsed for 24 hours in running tap water and finally rinsed in a stream of distilled water.

The test samples for obtaining correlations between wood moisture and electrical resistance were sections taken from the base and from the upper part of young stems of Douglas-fir, western hemlock, western red cedar, and black cottonwood; three trees of each species were sampled. Each section consisted of a disc, free from knots and defects, the basal ones being approximately $4^{\prime \prime}$ in diameter by $5^{\prime \prime}$ long and the upper ones $2 \frac{1}{2}$ " in diameter by $4^{\prime \prime}$ long. Duplicate sections were taken from adjacent positions in the stem. After each section was debarked it was weighed then one duplicate was ovendried at $105^{\circ} \mathrm{C}$ to constant weight while the oven-dry weight of the adjacent duplicate was calculated by proportion. The calculated dry weight was used as an approximation until the end of the experiment when the actual over-dry weight of the test section was determined. This precaution was used to avoid undesirable effects in the test sections such as checking as a result of rapid or too severe drying.

The test sections were dried slowly and when the wood was dry enough to be cleanly drilled, a slot 1 " long, $11 / 2$ " deep, and $3 / 32^{\prime \prime}$ wide was made with an electric drill and a router midway in the section parallel to the long axis and in a radial direction (Fig. 1). This size allowed the electrode to be inserted with a slight finger pressure. When the wood swelled on wetting the fit became snug but not excessively tight. Depending on the individual section, up to one third of the electrode was embedded in heartwood, the remainder in sapwood. Some sections were fitted with two electrodes.

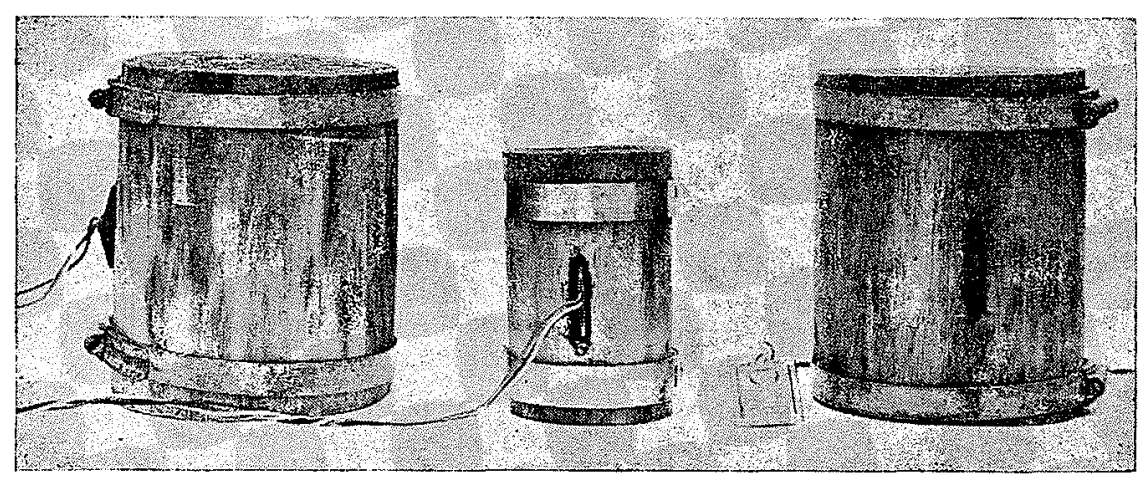

FIGURE 1. Mcthod of inserting an electrode into a stem section. Basal section on right has been bored ready for insertion of an electrode; electrode itself is to the left of the section. The upper section in the middle has the electrode inserted and the section on the left has the electrode inserted and sealed in with wax. 
In order to investigate the effect of tightness of fit, some slots were made narrower or wider than the standard. In some of the wider slots, sawdust was packed around the electrode to see if this would affect their performance.

The electrode was inserted into the slot so that the shoulders were flush with the surface of the section. The opening of the slot was sealed with sealing wax which was poured around the electric leads. The wax did not penetrate into the slot itself. As the section contracted on drying, the sealing wax was melted with a hot spatula and reapplied over the slot to make a tight seal. Two adjustable metal bands were fitted over each section to minimize checking. The bands were tightened as the section contracted.

After the electrodes had been inserted, each section was placed in distilled water and brought to maximum moisture content (M.M.C.) by alternately applying pressure and vacuum until its weight attained a stable maximum.

A resistance reading was taken on the section and it was then dried until it had lost weight equivalent to 5\% M.M.C. Drying was continued in steps of 5\% M.M.C. with readings being taken at each step, until the wood moisture was less than 10\% M.M.C. After each drying, the section was enclosed electrode uppermost in a polyethylene bag and kept at room temperature for a minimum of 40 hours because tests showed this period to be necessary for resistance readings to become stabilized.

Sections were dried by the following temperature schedule: $5^{\circ} \mathrm{C}$ for 8 hours; $20-25^{\circ} \mathrm{C}$ until the moisture content was reduced to $80 \%$ M.M.C.; $35^{\circ} \mathrm{C}$ until the moisture content was at approximately $25 \% ; 50^{\circ} \mathrm{C}$ for the remainder of the drying cycle.

After each drying cycle the section was brought to maximum moisture content and the drying procedure was repeated; at least 3 cycles were carried out with each section. In each cycle, readings in ohms were plotted against wood moisture content, expressed on an M.M.C. or an oven-dry weight basis. A balanced freehand curve was drawn for each section from the points of all cycles carried out with that section. The amount of variation about the curve for each section was expressed as the percentage of points that fell within the limits of $\pm 5 \%$ and $\pm 10 \%$ M.M.C. about the curve and also as the average variation of all points in the curve.

The accuracy of the method when the wood was increasing in moisture content was also investigated by taking readings in sections with moisture contents of about $10 \%$, then placing the sections in water so that absorption could take place but without directly exposing the electrode to water. The position of the section was changed from time to time to increase absorption. After the desired amount of water had been taken up the sections were allowed to equilibrate before a reading was taken. The process was repeated until no further gain in water was obtained.

In order to ascertain whether it was essential to leave the electrode continuously in place during the drying cycle, an oven-dried electrode was inserted into a section and a reading made after the equilibration period. The electrode was then removed and oven-dried again; the section moisture content was reduced by 5\% M.M.C. and the electrode was inserted and another reading made. 


\section{Trees}

Three naturally-established black cottonwood trees, 5 years old, approximately $20^{\prime}$ high and $4^{\prime \prime}$ in diameter were transplanted to $3^{\prime}$ wide by $2^{\prime}$ deep wooden tubs during dormancy. After the trees had put out new leaves and had been growing for 2 months without sign of having suffered from transplanting, 3 electrodes were inserted in each tree, one at the base, one at mid-height and one near the top. The electrodes were positioned at different points on the circumference of the stem and were inserted by the same means used for the sections except that neoprene putty instead of sealing wax was used to seal the slots. Because the green wood did not drill cleanly, a thin scalpel was used to smooth the sides of the slot. A plastic shield was tied to the stem above the electrodes to prevent accidental wetting. Atmospheric humidity was roughly controlled by means of a mist spray. Soil moisture was regulated by adding or withholding water, the soil surface being protected from accidental wetting by covering it with polyethylene sheeting. Three electrodes were buried in each tub to record the soil moisture.

The trees were kept in the tubs for periods up to 18 months during which droughts were alternated with periods of watering. Resistance of the soil and tree electrodes was read several times daily during periods of rapid change, and at longer intervals when changes were slow. At the end of the experiment; sections of the stems and blocks of soil containing the electrodes were removed to the laboratory. Wood moisture content/resistance curves were prepared for each section. The resistance readings which had been taken during the drought and watering cycles were converted to moisture contents (M.M.C.) using these curve values. The soil moisture content/resistance curves were obtained by the method described by Colman (1947) with the modification that the soil moisture was calculated as a percentage of maximum moistureholding capacity as determined by saturating the blocks of soil for 12 hours then allowing them to drain.

\section{RESULTS}

In all but two of the resistance/wood moisture content curves from conifer sections, over $85 \%$ of the points fell within the $\pm 10 \%$ limits and over $50 \%$ were within the $\pm 5 \%$ limits (Table 1 ). Douglas-fir curves had the largest and black cottonwood had the smallest percentage of points within the limits, the difference between these species being significant $(\mathrm{p}<.05)$. The difference between Douglas-fir and hemlock approached significance. Differences in average variation between species were not significant. In all species, small sections had more points within the limits than the large ones.

In general, the distribution of variation in any one curve appeared to depend on the moisture content and the species (Figs. 2-9). In all sections there was less variation below $20 \%$ of saturation than in other parts of the curve. In black cottonwood, the greatest variation appeared to be between 40 and $80 \%$, in cedar 20 and $80 \%$, and in Douglas-fir 30 and 50\%. In hemlock there appeared to be no consistent pattern of distribution.

There was no replicable relationship between the wood moisture/resistance curves and size of section or species (Table 2). However, there appeared to be certain characteristic features in the shape of the curve in some of the species. 
TABLE 1

Variation Of Readings In Moisture Content/Resistance Curves Using Colman Electrodes In Sections Of Tree Stems

\begin{tabular}{|c|c|c|c|c|c|c|c|}
\hline \multirow[b]{3}{*}{ Speeiea } & \multirow[b]{3}{*}{ Tree } & \multicolumn{3}{|c|}{ Upper seetions } & \multicolumn{2}{|c|}{ Basal seetions } & \\
\hline & & \multirow[b]{2}{*}{$\begin{array}{l}\text { Av. } \\
\text { variation } \\
\% \text { M.M.C. }\end{array}$} & \multicolumn{2}{|c|}{$\begin{array}{l}\text { Percentsges of } \\
\text { points within } \\
\text { limits of: }\end{array}$} & \multirow[b]{2}{*}{$\begin{array}{l}\text { Av. } \\
\text { varintion } \\
\text { \% M.M.C. }\end{array}$} & \multicolumn{2}{|c|}{$\begin{array}{l}\text { Peecentage of } \\
\text { points within } \\
\text { linitits of }\end{array}$} \\
\hline & & & $\begin{array}{l}+\mathbf{5} \% \\
\frac{\mathbf{M}}{\text { M.M.C. }}\end{array}$ & $\begin{array}{l}\text { M.M.C. } \\
+10 \% \\
\text { M.M. }\end{array}$ & & $\frac{ \pm 5 \%}{\text { M.M.C. }}$ & 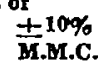 \\
\hline \multirow{4}{*}{$\begin{array}{l}\text { Douglas } \\
\text { fir }\end{array}$} & 1 & 2.3 & 92 & 100 & 8.4 & 54 & 79 \\
\hline & 2 & 2.7 & 100 & 100 & 3.5 & 81 & 100 \\
\hline & 3 & 2.9 & 79 & 100 & 2.3 & 79 & 96 \\
\hline & Av. & 2.6 & 90 & 100 & 4.7 & 71 & 98 \\
\hline \multirow[t]{4}{*}{ Hemlock } & 1 & 4.5 & 68 & 100 & 2.2 & 71 & 98 \\
\hline & 2 & 4.4 & 67 & 92 & 8.6 & 34 & 63 \\
\hline & 3 & 2.3 & 88 & 100 & 7.2 & 32 & 87 \\
\hline & Av. & 3.7 & 74 & 97 & 6.0 & 46 & 86 \\
\hline \multirow[t]{4}{*}{ Red cedar } & 1 & 5.2 & 70 & 98 & 3.8 & 58 & 92 \\
\hline & 2 & 5.5 & 66 & 88 & 5.5 & 62 & 95 \\
\hline & 3 & 2.8 & 81 & 98 & 3.9 & 78 & 96 \\
\hline & Av. & 4.5 & 74 & 95 & 4.4 & 66 & 96 \\
\hline \multirow{4}{*}{$\begin{array}{l}\text { Black } \\
\text { cottonwood }\end{array}$} & 1 & 3.3 & 54 & 84 & 3.5 & 72 & 93 \\
\hline & 2 & 2.8 & 62 & 74 & 9.5 & 28 & 45 \\
\hline & 3 & 3.9 & 50 & 75 & & & \\
\hline & Av. & 3.3 & 55 & 78 & 6.5 & 50 & 69 \\
\hline
\end{tabular}

Cedar curves were usually concave in the higher moisture percentages; black cottonwood curves were concave over almost the whole range; Douglas-fir and hemlock curves were more sinuous.

The curves (not shown) from sections in which moisture content was being increased were incomplete because the moisture content could not be increased above $60 \%$.

The insertion of a dry electrode into a section produced a curve which was roughly similar to the curves from electrodes which were left continuously in place but had greater variation.

Tightness of fit and packing with sawdust had no perceptible effect on the electrode readings.

When an electrode from one section was inserted in another section, the resulting curve resembled the curve for the section to which the electrode had been transferred rather than the one for the section from which it had been taken, even if the two original curves were very dissimilar in shape. The curves from two electrodes in the same section were similar in shape although not identical. 
SEPTEMBER, 1965

TABLE 2

Comparison Of Resistance/Wood Moisture Content Relationship By SPECIES AND SEction

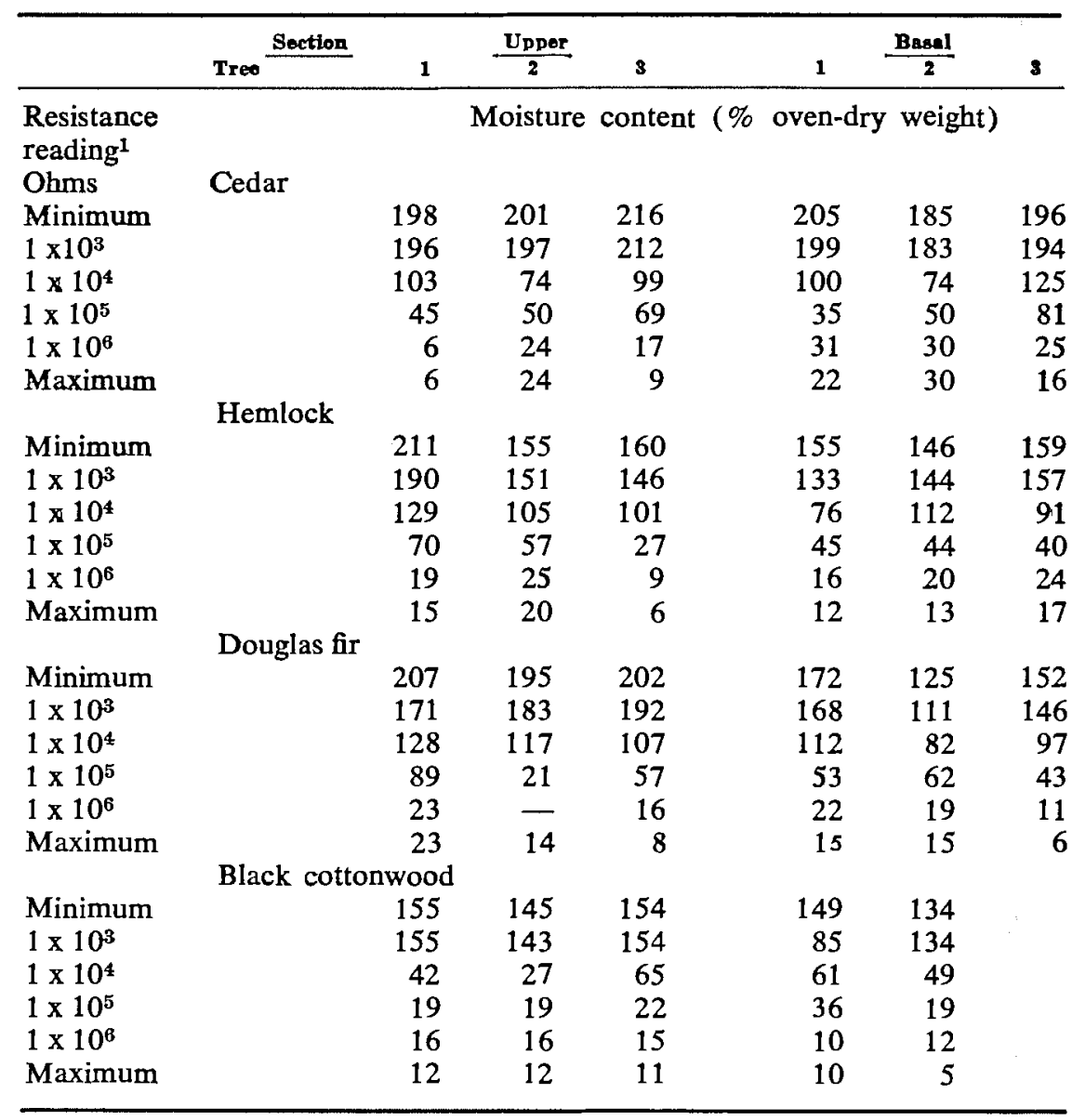

${ }^{1}$ The minimum reading obtained in each case was less than 1,000 ohms, and the maximum was greater than 1 megohm.

FIGURES 2-9 Correlation of electrical resistance with wood moisture content in stem sections of three conifers. The different symbols represent separate cycles as follows: $x$ is 1 st cycle; solid circle is 2 nd cycle; empty triangle is 3 rd cycle; solid triangle is 4 th cycle; empty circle is 5 th cycle; solid square is 6 th cycle.

FIGURES 2 \& 3 Western red cedar, basal and upper section respectively.

FIGURES 4 \& 8 Western hemlock, basal and upper section respectively.

FIGURES $6 \quad \& \quad 7$ Douglas-fir, basal and upper section respectively.

FIGURES \& \& 9 Black cottonwood, basal and upper sections respectively. 


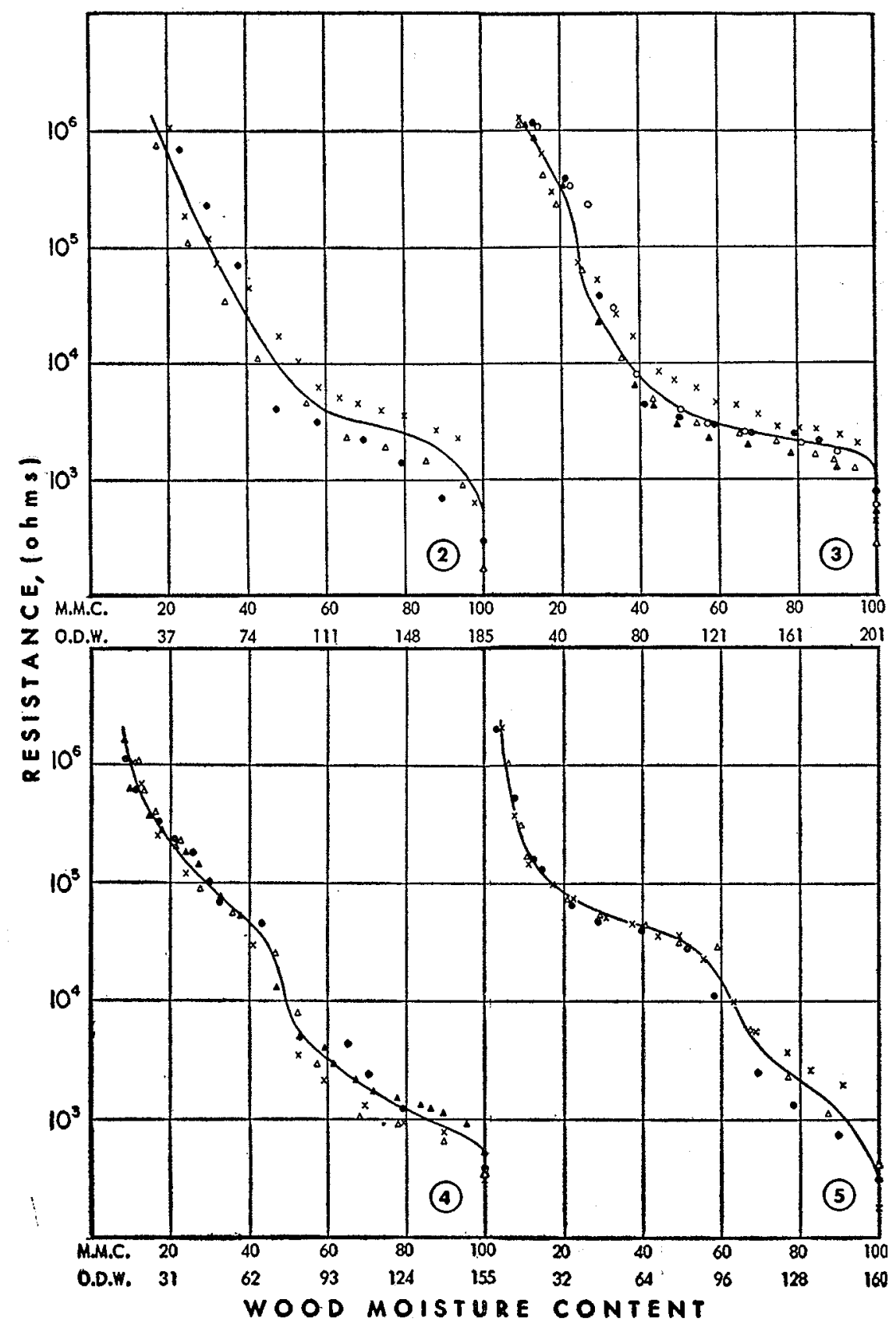




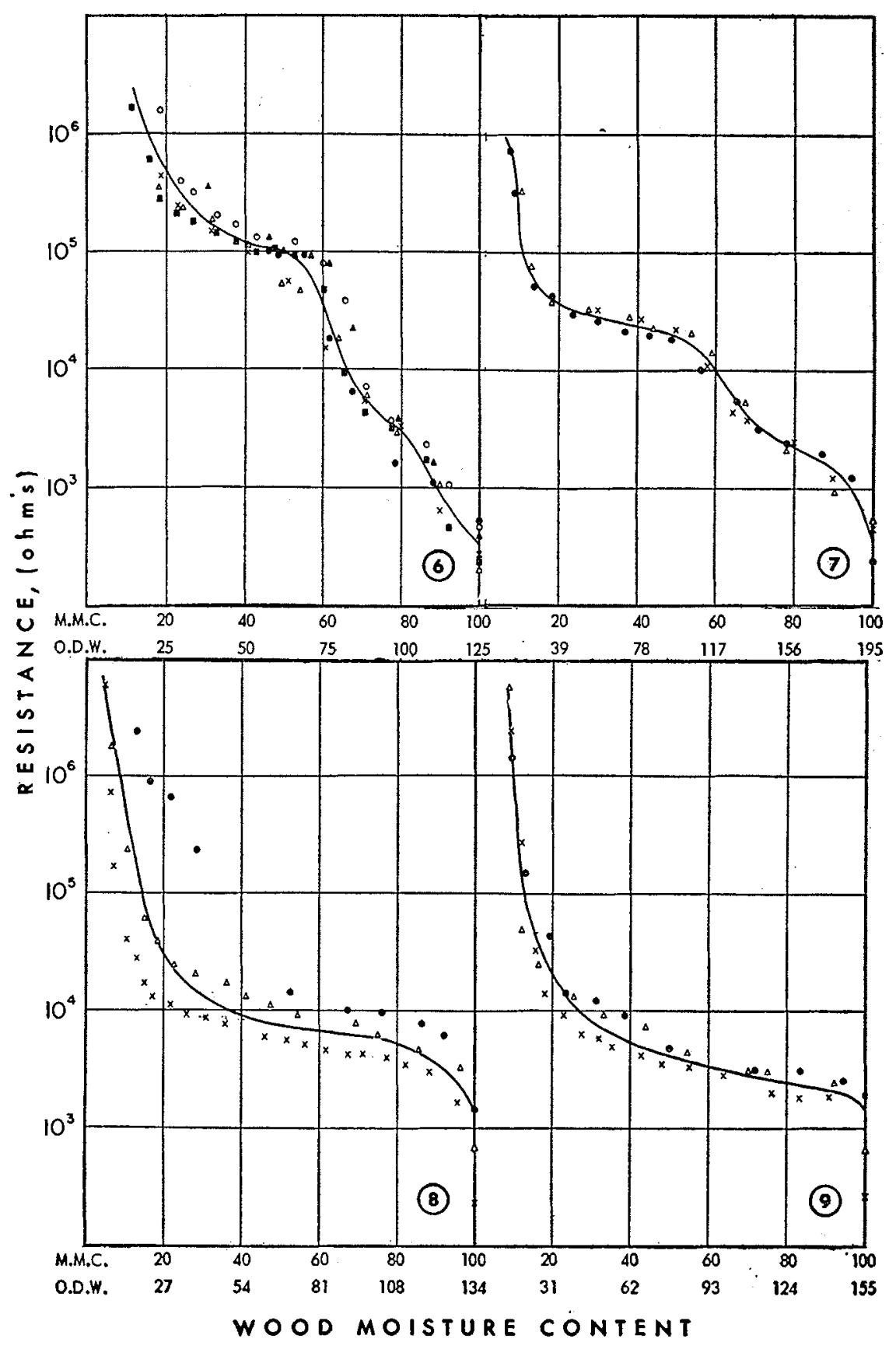



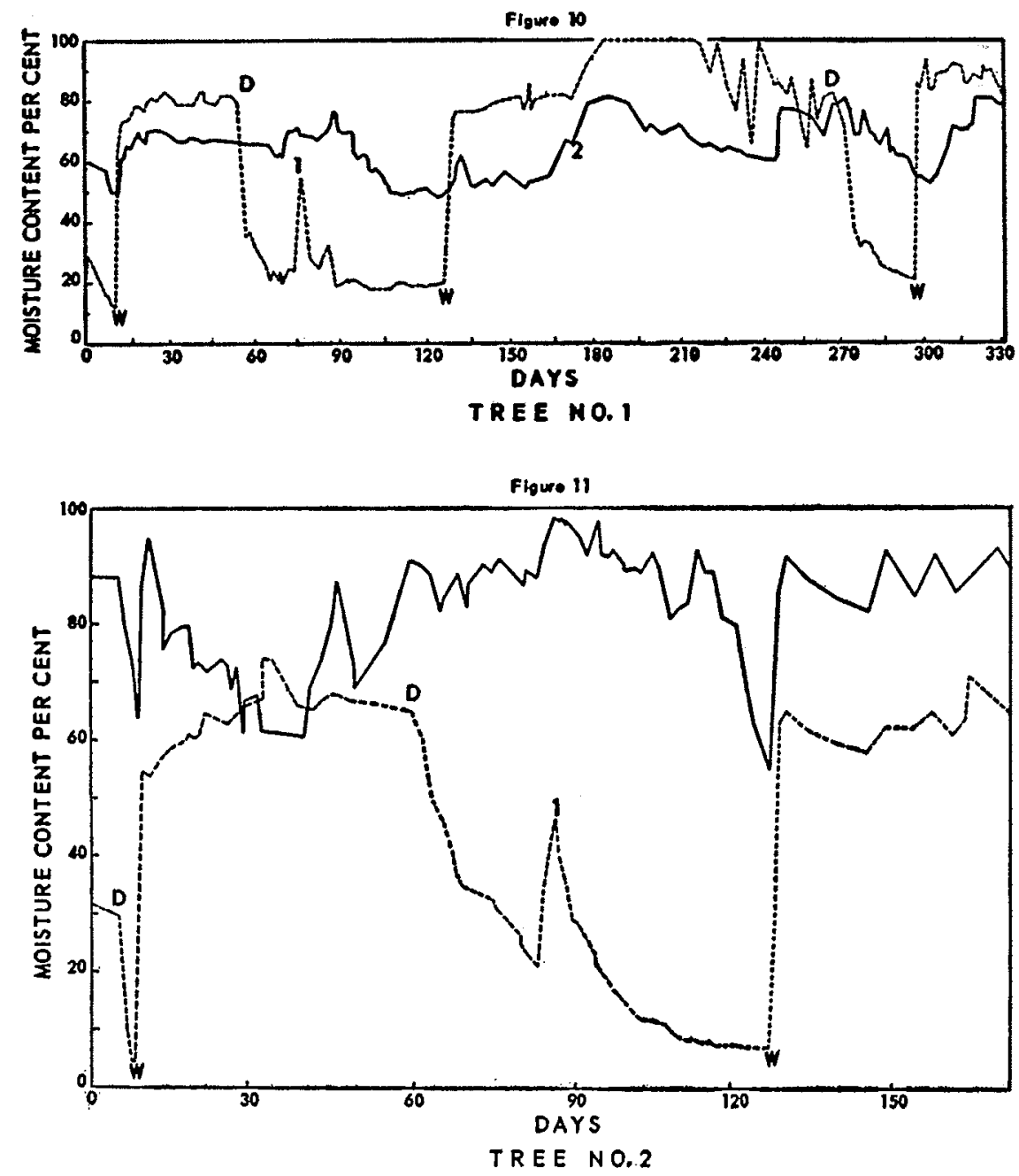

FIGURES 10-12 Trend of stem moisture content (solid line) in living cottonwood trees and soil moisture content (broken line) as indicated by Colman electrodes. $\mathrm{D}=$ watering withheld; $W=$ watering commenced.

FIGURE 10. Point 1: Water accidentally seeped into soil, interrupting the drought. Point 2: Inorganic fertilizer added to the soil.

FIGURE 11. Point 1: Water accidentally seeped into soil.

FIGURE 12. Note diminishing changes in tree moisture content in $3 \mathrm{rd}$ and $4 \mathrm{th}$ drought-watering cycles. 


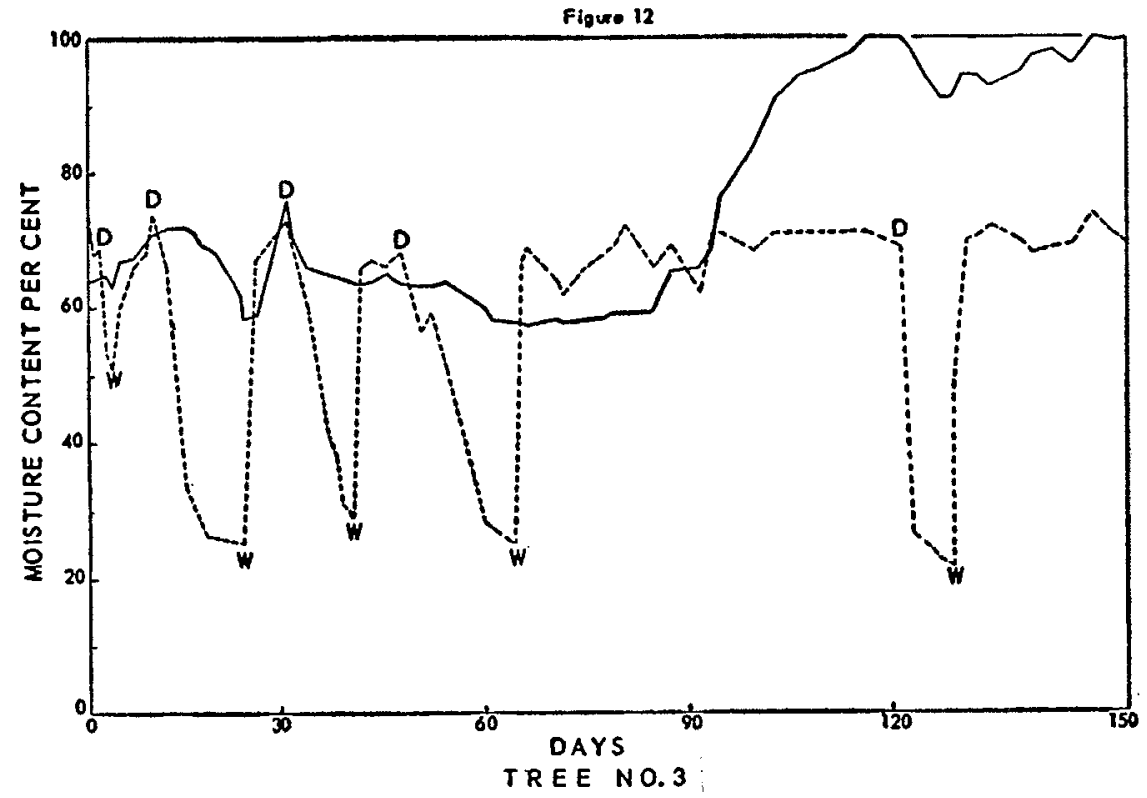

Stem moisture content of the trees (Figs. 10-12) was calculated as the average of readings from all electrodes inserted in the tree. In all trees, the resistance readings indicated declines in moisture content during drought periods and increases after the soil was watered. The declines were greater and more rapid in the first or second drought periods than in subsequent ones. Changes in readings when the soil was being wetted were generally more rapid than when it was being dried out. After inorganic fertilizer was added to the soil around Tree No. 1, (Fig. 10, point 2) the resistance readings indicated an increase in tree moisture followed by a decline although the watering procedure had remained unchanged throughout.

The trees became defoliated during some of the drought periods, but always put out fresh foliage and showed no signs of injury. There was no apparent traumatic effect around the wood in which electrodes had been inserted.

\section{Discussion}

With the exception of a general resemblance in shape, the resistance/wood moisture curves of each tree species showed no characteristics in common from which a standard curve for a species could be drawn. Each stem section produced a highly replicable but unique curve. Even when electrodes were exchanged between sections of different species with greatly differing curves, the resulting curves were very similar to the original ones. Two electrodes in one section produced essentially the same curves. It must be 
inferred, therefore, that any variation which exists between electrodes is a minor factor, but that the properties of individual sections are the major influence in producing a curve of certain shape and proportions. It is possible that careful selection of electrodes would further decrease the variation in the curves.

Although tightness of fit of the electrode in the wood made no perceptible difference to the readings, it might be desirable to modify existing electrodes for easier insertion and closer contact of fibreglas with the wood.

Because variation increased with section size, presumably due to non-uniform distribution of moisture, it might be desirable to derive the curves from more than one electrode in a section, the number depending on the accuracy required. The foregoing results indicated that one electrode is sufficient in most conifer sections of dimensions $21 / 2$ " diameter by $4^{\prime \prime}$ long to provide accuracy of $\pm 10 \%$, but is insufficient in black cottonwood and in some of the larger conifer sections. Results from using the electrodes to measure increases in moisture content were inconclusive because of the difficulty in obtaining the higher wood moisture contents. There was a greater variation in these curves than in the ones obtained by drying, but this may have been attributable to a nonuniform diffusion of moisture through the wood. Inserting a dry electrode before each reading did not produce accurate results.

On the assumption that the tree moisture content is largely determined by soil moisture, the evidence from the experiments with living trees indicates it can be measured using the Colman electrode. Differences in magnitude and speed of response to drought and watering among the three trees and between different cycles in one tree could be caused by many factors and do not necessarily cast doubt on the accuracy of the method. In fact, the range of moisture contents using the electrodes was nearly the same as that found in black cottonwood using gravimetric methods (Bloomberg 1962). One obvious effect was that of application of fertilizer to Tree 1 causing readings to rise even though the amount of soil water was approximately the same.

\section{CONCLUSIONS}

The above-described method should be applicable to a number of investigations requiring rapid and repeated measurement of wood moisture contents over a wide range and in which a variation up to $\pm 10 \%$ M.M.C. is acceptable. With careful electrode selection, this variation can probably be further reduced. Such applications are the changes in moisture of logs, stumps or standing dead timber. The application of the method to living trees shows promise, but more extensive testing should be carried out to establish its reliability.

\section{ACKNOWLEDGEMENTS}

The author appreciatively acknowledges the critical reviews of the manuscript by Mr. M. Salamon, Research Officer, Vancouver laboratory and Dr. D. G. Miller, Research Officer, Ottawa laboratory of the Forest Products Research Branch, and Dr. R. E. Foster, formerly head of forest pathology investigations, and research officers of the Victoria laboratory, Forest Entomology and Pathology Branch. 


\section{REFERENCES}

BLOOMBERG, W. J. 1962. Cytospora canker of poplars: the moisture relations and anatomy of the host. Can. J. Botany 40, 1281-1292.

COLMAN, E. A. 1947. Manual of instructions for use of the fibreglas soil-moisture instrument. Calif. For. and Range Expt. Sta., 20 pp.

J'AMES, W. L. 1958. Electrical moisture meters for wood. For. Prod. Lab., U. S. Dept. Agric. Rept. No. 160.

JOHNSTON, D. D. and R. H. WYNANDS 1958. Determination of moisture in timber. Wood 23, 458-462.

KEYLWERTH, R. and D. NOACK 1956. Uber den Einfluss höheree Temperaturen auf die elektrische Holzfeuchtigkeits-messung nach dem Wilderstandsprinzip. Holz als Roh-und Werkstoff. Mai 1956, 162-172.

MOSES, C. S. and T. C. SCHEFFER 1959. Using a resistance-type wood moisture meter to appraise decay hazard. For. Prod. Lab., U. S. Dept. Agric. Rept. No. 2147. 